\title{
Enzymatic Modification of Paper Fibres
}

\author{
H. PALA, M. MOTA and F.M. GAMA* \\ Centro de Engenharia Biológica-IBQF, Universidade do Minho, Largo do Paço, 4719 Braga codex, Portugal
}

The enzymatic mode of action in paper fibre upgrading is still uncertain. In an attempt to clarify how enzymes modify pulp and paper properties, several parameters were analysed in the present work: (i) thermal analysis of the water-solid surface interactions; (ii) fibre cake permeability; (iii) particle size analysis. The results obtained suggest that enzymes modify the interfacial properties of fibres, increasing the water affinity, which in turn change the technical properties of pulp and paper, such as drainability and strength. The modification of paper and pulps following a treatment with cellulosebinding domains further supports this hypothesis.

Keywords: Paper pulps; Enzymes; Thermal analysis; Permeability; Cellulose-binding domains; Fibre cake

\section{INTRODUCTION}

Enzymatic treatment of paper pulps has been investigated for several years, with the goal of achieving improved inter-fibre bonding and fibre dewatering. However, in most cases it is not possible to accomplish both purposes simultaneously (Pommier et al., 1989; Jackson et al., 1993; Stork and Puls, 1994; Pere et al., 1995; Mansfield et al., 1996; Ryan et al., 1998). In order to do so, it is probably necessary to fully understand the enzymatic mechanism.

Pommier et al. (1989) describe the enzymatic action as a "peeling effect". These authors suggest that enzymes defibrillate fibres by removing molecules with high water affinity, but with a small contribution to the overall hydrogen bonding potential of the fibres. This reduction in pulp-water interactions allows better drainage of the pulp, without affecting the final mechanical properties of the paper. An intensive enzymatic reaction leads to both intrinsic fibre strength and fibre length reduction, and excessive fines production. As a consequence, the paper strength is dramatically affected.

Jackson et al. (1993) suggest that enzymes can either flocculate or hydrolyse fines and remove fibrils from the surface of large fibres. According to these authors, the enzyme-aided flocculation occurs when a low enzyme dosage is used. In this case, fines and small fibre particles aggregate with each other or with the larger fibres, decreasing the amount of small particles in the pulp and consequently improving pulp drainage. For higher enzyme concentration, flocculation becomes less significant, and fragmentation of the fibres begins to predominate.

Enzyme specificity must also be considered. As shown by Pere et al. (1995), endo and exoglucanases affect paper technical properties differently. Endoglucanases can lower pulp viscosity and thus dramatically reduce the paper strength. The differences in enzyme activity are attributed to the different modes of action. Endoglucanases are more active on amorphous cellulose and randomly attack the inner part of the cellulosic chain, whereas exoglucanases can hydrolyse both crystalline and amorphous cellulose by removing cellobiose from the terminal part of the cellulose chains (Henrrissat, 1994). Although considered more detrimental to fibres, endoglucanase action is probably the main determinant of drainage improvement (Jackson et al., 1993; Stork and Puls, 1994; Viesturs et al., 1996).

Keeping in mind the previous considerations, we believe that whenever enzymatic hydrolysis is small, other factors may be invoked to explain drainage improvements. Surface properties may be modified, not only because of enzymatic hydrolysis of the outer layers of the fibre, but also because of the adsorption

*Corresponding author. Tel.: + 351-253-604400. Fax: + 351-253-678986. 
of enzyme molecules onto the fibre surface. It could be speculated that changes in fibre-water interaction, induced by the presence of enzyme molecules, might be the factor responsible for drainage and strength modification. The experimental results presented in this work support this hypothesis.

\section{MATERIAL AND METHODS}

\section{Enzyme}

A commercial cellulase from Trichoderma reesei, Celluclast 1.5L (Novo Nordisk) was used. The protein amount $(94 \mathrm{mg} / \mathrm{ml})$ was determined by the Bradford method, using serum albumin as standard (Bradford, 1976). Total cellulase (57 FPU/ml), Endoglucanase $(26 \mathrm{U} / \mathrm{ml})$ and Xylanase $(680 \mathrm{U} / \mathrm{ml})$ activities were measured by the filter paper, carboxymethylcellulase, and the xylan oat-spelt assays, respectively (Pala et al., 2001). Released sugars were measured by the dinitrosalicylic acid method, using glucose as standard (Bernfeld, 1955).

\section{Cellulose-binding Domains}

The cellulose-binding domains (CBD) were obtained from Celluclast 1.5L following proteolytic digestion, according to the protocol described in Lemos et al. (2000). The protein in the CBD's solution was measured by the Bradford assay (Bradford, 1976).

\section{Materials}

Cellulose powders: (i) Sigmacell 101 (Sigma); (ii) Whatman CF11 (Whatman Chemical Separation, Ltd. England).

Paper pulps: (i) old paperboard containers, which represented a mixture of $60 \%$ Kraft paper, $20 \%$ fluting and $20 \%$ test liner; (ii) primary pulp (currently used for paperboard production), which was composed of $60 \%$ Pinus pinaster, 10\% Eucalyptus globulus and 30\% Pinus caribaea. Both samples were kindly supplied by Portucel viana.

\section{Fibre Fractionation}

The secondary pulp, obtained through the disintegration of the old paperboard containers, was fractionated using a Bauer-McNett fibre-length classifier, according to the proposed standard routine (Tappi $233 \mathrm{~cm}-82$ ). Two of the smaller fibre-length fractions were collected: $<200$ mesh and 200-140 mesh. The smallest fraction $(<200$ mesh) was recovered by filtering the liquid released by the Bauer-McNett apparatus through a glass filter no. 2.

The fibre length in the collected fractions was estimated by assuming that fibres cannot pass through the screen if their length is more than twice the greatest width of the screen holes: this means that for the smallest fraction $(<200$ mesh) fibres will be assumed to have a length below $0.209 \mathrm{~mm}$, whereas for the range 200-140 mesh fibres will be assumed to be in the range $0.209-0.297 \mathrm{~mm}$. Although fibre characteristics (flexibility, curliness, fibrillation) may affect fractionation, this approach allows for an estimation of fibre size, especially when separation occurs in the final compartments of the Bauer-McNett, as is the case (Clark, 1985). The size of the screened fibres was further measured with a Galai laser granulometer.

\section{Enzymatic Treatment of the Samples}

Paper pulps (a mass equivalent to $30 \mathrm{~g}$ of oven dried (o.d.) pulp) were disintegrated with a blender in sodium citrate buffer $0.05 \mathrm{M}, \mathrm{pH} 5.0$, for $10 \mathrm{~min}$. The enzyme was added to a mixture with $3 \%$ consistency, at $50^{\circ} \mathrm{C}$, with continuous and slow mixing. The enzymatic preparation was diluted prior to being added to the pulp, to achieve better dispersion. The enzyme was inactivated (as confirmed by filter paper hydrolysis assays) by boiling the pulp for $5 \mathrm{~min}$ and the fibres were recovered by filtration. The filtrate was forced to pass through the fibre cake so that the loss of shorter fibres could be avoided. Reducing sugars in the filtrate were measured, using the DNS method (Bernfeld, 1955). Control assays performed with denatured enzyme were prepared in parallel with assays using active enzyme.

As the CBD solutions did not show any hydrolytic activity (Lemos et al., 2000), pulp treatment with CBD was done under the same experimental conditions, but thermal deactivation was omitted. In this case, the control assays were made in the absence of CBD.

Several enzyme/CBD dosages and reaction times were used: (i) CBD, $1.4 \mathrm{mg}$ protein/g o.d. pulp, $30 \mathrm{~min}$ (pulp and paper characterisation in Pala et al., 2001); (ii) enzyme, 0.3-0.6 FPU/g o.d. pulp, $30 \mathrm{~min}$ (Pala et al., 2001); (iii) enzyme, 2.8 FPU/g o.d. pulp, $15 \mathrm{~min}$ and $4 \mathrm{~h}$ (thermal analysis and flexibility measurements).

In order to detect changes in the size of the smaller fibres/fines, during the enzymatic reaction, experiments with the fractionated secondary pulp followed a slightly different protocol. The reaction $(2.8 \mathrm{FPU} / \mathrm{g}$ o.d.) was done at a very low consistency (approximately $0.05 \%$ ). The suspended fibres were directly analysed in the Galai CIS-100 particle analyser after $30 \mathrm{~min}, 4$ and $14 \mathrm{~h}$ of reaction.

\section{Physical and Mechanical Properties Determination}

Handsheet preparation and determinations of the pulp and paper properties followed the usual 
standard procedures: drainage rate (ISO 5267/1), burst (ISO 2758), tensile strength (ISO 1924/2) and tear (ISO 1974).

\section{Flexibility Measurements}

Fibre flexibility measurement was based on Steadman and Mohlin's method, which simulates the chemical linkages and mechanical deformation of fibres in a paper sheet. In this method, fibres are forced to bend over and wrap around a metallic wire representing a fibre of known dimensions. The more flexible the fibre, the more it will wrap around the wire. Sample slides were automatically prepared in the Sample maker apparatus (CyberMetrics). Wet fibre flexibility Index (\% WFF) was measured using the Cyberflex analyser (CyberMetrics). The overall pulp flexibility considers the absolute flexibility values obtained for each fibre and is expressed as an index ranging from 0 to 100, allowing a direct comparison of different pulps (Cyberflex user manual, 1999; Petit-Conil et al., 1999).

\section{X-ray Diffraction}

X-ray diffraction was used to determine the cellulose crystallinity. A Rigaku diffractometer was operated at $30 \mathrm{kV}$ tube voltage and at $20 \mathrm{~mA}$. The wavelength of the $\mathrm{Cu} / \mathrm{K} \alpha$ radiation source was $0.154 \mathrm{~nm}$. The samples were scanned over a range of $2 \theta$ from 5 to $50^{\circ}$ (Bragg angle), with a scanning velocity of $0.6^{\circ} / \mathrm{min}$. A peak resolution program was used to calculate the crystallinity index (CrI). As proposed by Hindeleh and Johnson (1972; 1974; 1978), CrI was calculated as the ratio of the resolved peak area to the total area under the unresolved peak profile.

\section{Thermal Analysis}

Differential scanning calorimetry (DSC) and Thermogravimetry (TG) were used to determine the specific enthalpy of dehydration. For this purpose, the samples were preconditioned in a $100 \%$ relative humidity chamber, for 10 days, at room temperature (approximately $25^{\circ} \mathrm{C}$ ). This was the necessary period to achieve the adsorption equilibrium corresponding to a constant final weight. Each sample, of approximately $5 \mathrm{mg}$, was weighed in an aluminium vessel and closed with perforated lids, to allow the release of evaporated water during the assays. The closed vessels were again placed in the same chamber for 5 days, to re-establish water equilibrium. The analyses were performed in model 50 TGA and DSC equipment, from Shimadzu. In both cases, assays were performed with a heating rate of $5^{\circ} \mathrm{C} / \mathrm{min}$, from $20-25$ to $200^{\circ} \mathrm{C}$, in the absence of purge gas. Considering the good reproducibility of the measurements, as shown previously by Dourado et al. (1999), only six repetitions were performed for each sample.

The thermal analysis of fibrous samples (such as the paper pulps used in this work) raises difficulties associated with the reproducibility of the surface-tovolume ratio of the sample. Additionally, fibres contain a large amount of air, which has a low heat conductivity. Although preventing the limited diffusion of evolved gases through the sample (which would significantly alter the thermal analysis results), it was necessary to pack the sample tightly into the sample vessel in order to minimise thermal gradients. The methods commonly suggested to simplify sample preparation involve grinding or cutting the fibres (Brown, 1988; Harakeyama and Quinn, 1995). In the present work, fearing for the integrity of the samples, we decided not to alter the samples and to select apparently homogeneous pieces of the same size to perform the analysis.

\section{Fibre Cake Permeability}

A cylindrical filter unit with a layer support was used. The layer support consists of two different size wire nets, with a minimum porosity of 200 mesh. The paper pulp (a mass equivalent to $2-4 \mathrm{~g}$ of o.d. pulp, depending on the pulp characteristics and the applied pressure drop, suspended in $200 \mathrm{ml}$ of water) was disintegrated for $10 \mathrm{~min}$ and added to the filtration unit, thus forming a bed of particles on the top of the support. Before applying a stronger filtration pressure, the water was allowed to drain at atmospheric pressure. After compressing the filtration cake for $5 \mathrm{~min}$ at the desired pressure drop, the filtration unit was filled with water and the volume was kept constant for $10 \mathrm{~min}$, in order to let fibres settle. The water flowing time was then measured as a function of the flowing distance (usually $4 \mathrm{~cm}$ ). A total of six measurements were performed for each assay. Except for the atmospheric pressure assay, the tested filtration pressures were established with a vacuum pump (Millipore XX5522050) operating in the range $100-500 \mathrm{mmHg}$. Each experimental condition (392; 13,328; 39,984 and $66,640 \mathrm{~kg} / \mathrm{ms}^{2}$ ) was tested ten times.

This work was based on the traditional model for liquid flow through porous media proposed by Kozeny-Carman (Coulson and Richardson, 1984). The permeability and resistance coefficients of the pulp mat were determined according to Eqs. (1) and (2). It has been considered that the resistance offered by the supporting nets is not important after the pulp cake has been formed. As cake resistance depends on the applied pressure drop, it was assumed that the pulps present a compressible behaviour and Eq. (3) was used to determine 
the cake compressibility coefficient. Finally, porosity was calculated with Eq. (4).

$$
\begin{gathered}
B=\frac{u \mu L}{\Delta P} \\
\alpha=\frac{1}{B} \\
\alpha=\alpha_{0} \Delta P^{\mathrm{s}} \\
C_{\mathrm{s}} V=L A(1-\epsilon) \rho_{\text {solid }}
\end{gathered}
$$

where $B$ is the coefficient of permeability $\left(\mathrm{m}^{2}\right), u$ the filtration velocity $(\mathrm{m} / \mathrm{s}), \mu$ the viscosity of the filtrate $(\mathrm{kg} \mathrm{m} / \mathrm{s}), L$ the thickness of the bed $(\mathrm{m}), \alpha$ the specific bed resistance $\left(\mathrm{m}^{-2}\right) ; \Delta P$ the pressure drop through packed bed $\left(\mathrm{kg} / \mathrm{ms}^{2}\right)$, $s$ the compressibility coefficient of the bed (adimensional), $\epsilon$ the porosity of the bed (adimensional), $C_{\mathrm{s}} V$ the solid dry weight in the bed $(\mathrm{kg}), A$ the cross section area of the bed $\left(\mathrm{m}^{2}\right), \rho_{\text {solid }}$ the density of the solid $\left(\mathrm{kg} / \mathrm{m}^{3}\right)$, and $\alpha_{0}$ is the specific bed resistance at the beginning of filtration $\left(\mathrm{s}^{2} / \mathrm{kgm}\right)$.

\section{Particle Size Characterisation}

The particle size distribution of enzymatically treated and non-treated samples was measured using the Galai CIS-100. This instrument is a laserbased analysis system, where the size of each particle is calculated from the time of interaction between the particles and the laser beam, according to the theory of Time of Transition (CIS-100 Operation Manual, 1994). The suspended cellulose fibres were transferred into a magnetic stirred cell and scanned for a size range between 2 and $600 \mu \mathrm{m}$.

\section{RESULTS AND DISCUSSION}

In previous work (Pala et al., 2001), it was shown that although being very efficient for drainage improvement, enzymatic preparations such as Celluclast could be detrimental to paper strength.
Furthermore, it was interesting to note that short incubations were sufficient for enzymes to provide such modifications. Additionally, when a CBD solution was applied to the same pulp, a simultaneous increase in drainage and paper strength was achieved. Table I summarises those results, which indicate that: (1) CBDs are very promising tools for fibre modification, and (2) hydrolytic activity is not the only phenomenon that should be considered when studying enzymatic fibre modification. A new perspective and experimental approach is therefore necessary to understand the effect of enzymes on paper fibre modification. In this work, the effect of enzymes on fibres surface properties was analysed by thermal analysis, and a cake filtration assay was used to characterise the water drainage through compressed paper fibres, a situation not accessed when using the SchopperRiegler method, the Canadian Standard Freeness tester or the Water Retention values (WRV) measurement. Particle size, crystallinity and flexibility were also determined.

\section{Thermal Analysis}

By accessing both the amount and relative strength of water adsorption on the fibres surface, thermal analysis gives more information than the commonly used WRV method. This approach was previously used to characterise the surface and interfacial properties of commercial cellulose powders, before and after enzyme adsorption (Dourado et al., 1999). In that case, the analysis was performed in the presence of argon ( $40 \mathrm{ml} / \mathrm{min})$.

As shown in Table II, the absolute enthalpy of dehydration is different under the new experimental conditions. However, the results show the same previously reported trend (Dourado et al., 1999): the more amorphous cellulose (Sigmacell 101) adsorbs a larger and more strongly bound amount of water,

\begin{tabular}{|c|c|c|c|c|c|c|c|c|c|}
\hline \multirow[b]{2}{*}{ Treatment } & \multicolumn{2}{|c|}{ Drainage } & \multicolumn{2}{|c|}{ Tensile index } & \multicolumn{2}{|c|}{ Burst index } & \multicolumn{2}{|c|}{ Tear index } & \multirow[b]{2}{*}{$\%$ Solubilisation } \\
\hline & ${ }^{\circ} S R$ & $\Delta \%$ & $\mathrm{Nm} / \mathrm{g}$ & $\Delta \%$ & $\mathrm{kPam}^{2} / \mathrm{g}$ & $\Delta \%$ & $m N m^{2} / g$ & $\Delta \%$ & \\
\hline \multicolumn{10}{|l|}{ Primary pulp-Celluclast 1.5L } \\
\hline Control (FPU/go.d. $30 \mathrm{~min})$ & 13 & & 39 & & 2.9 & & 19.5 & & - \\
\hline$(0.5 \mathrm{mg}$ protein $\sim 0.3 \mathrm{FPU} /$ g o.d. $30 \mathrm{~min})$ & & 0 & & -2 & & -3 & & -8 & 0.2 \\
\hline (1.0 mg protein $\sim 0.6 \mathrm{FPU} / \mathrm{g}$ o.d. $30 \mathrm{~min})$ & & 0 & & +13 & & 0 & & -15 & 0.6 \\
\hline \multicolumn{10}{|l|}{ Secondary pulp-Celluclast 1.5L } \\
\hline Control (FPU/g o.d. $30 \mathrm{~min})$ & 53 & & 39.9 & & 2.7 & & 9.5 & & - \\
\hline$(0.7 \mathrm{mg}$ protein $\sim 0.4 \mathrm{FPU} /$ g o.d. $30 \mathrm{~min})$ & & -32 & & -7 & & -19 & & -13 & 1.1 \\
\hline (1.0 mg protein $\sim 0.6 \mathrm{FPU} / \mathrm{g}$ o.d. $30 \mathrm{~min})$ & & -38 & & -8 & & -22 & & -21 & 1.3 \\
\hline \multicolumn{10}{|l|}{ Secondary pulp-CBD } \\
\hline Control (mg protein/g o.d. $30 \mathrm{~min}$ ) & 50 & & 36.5 & & 2.3 & & 9.2 & & - \\
\hline$(1.4 \mathrm{mg}$ protein $/$ g o.d. $30 \mathrm{~min})$ & & -14 & & +7 & & +9 & & -2 & 0 \\
\hline
\end{tabular}
revealing a higher hydrophilic character. The higher concentration of hydroxyl groups in the samples

TABLE I Effect of the enzymatic/CBD treatment on the properties of pulp and paper*

* The technical parameters after enzymatic treatment are presented as the variation (second column) relatively to the control (first column). 
TABLE II Thermal analysis results for the commercial powder cellulose samples

\begin{tabular}{|c|c|c|c|c|c|}
\hline Sample & $\begin{array}{l}\text { Adsorbed water* } \\
\text { (mg } \mathrm{H}_{2} \mathrm{O} / m g \\
\text { dry solid) }\end{array}$ & $\begin{array}{l}\text { Enthalpy of } \\
\text { dehydration * } \\
\left(\mathrm{J} / \mathrm{g} \mathrm{H}_{2} \mathrm{O}\right)\end{array}$ & $\begin{array}{l}\text { Adsorbed water } \\
\left(m g \mathrm{H}_{2} \mathrm{O} / m g\right. \\
\text { dry solid })\end{array}$ & $\begin{array}{l}\text { Enthalpy of } \\
\text { dehydration } \\
\left(\mathrm{J} / \mathrm{g} \mathrm{H}_{2} \mathrm{O}\right)\end{array}$ & $\mathrm{CrI}(\%)$ \\
\hline Sigmacell 101 & 0.37 & 1580 & 0.34 & 2470 & $-^{+}$ \\
\hline $\begin{array}{l}\text { Sigmacell } 101 \text { (enzymatically } \\
\text { treated with Celluclast) }\end{array}$ & 0.36 & 1890 & Not determined & Not determined & Not determined \\
\hline Whatman CF11 & 0.21 & 1360 & 0.21 & 2100 & 77 \\
\hline $\begin{array}{l}\text { Whatman CF11 (enzymatically treated } \\
\text { with Celluclast) }\end{array}$ & 0.28 & 1930 & Not determined & Not determined & Not determined \\
\hline
\end{tabular}

* Previous work by Dourado et al. (1999). ${ }^{+}$The amorphous Sigmacell 101 did not allow crystallinity determination because of the poorly resolved profiles, even at low scanning rates.

with lower crystallinity favours water adsorption, which was expected.

The results in Table III allow for a similar analysis in respect to secondary and primary pulps. When comparing the Blank samples, one may observe that the amount of adsorbed water is higher in the primary fibres, and that the heat of dehydration is not significantly different in the two pulps. According to previous work, this might mean that primary fibres are more amorphous (Bertran and Dale, 1986). This hypothesis was confirmed by X-ray diffraction. Crystallinity values are $66 \%$ for secondary fibres and $58 \%$ for the primary ones. The higher crystallinity of the recycled pulp is probably related to the drying stage (Marton et al., 1993; Nazhad and Paszner, 1994). Additionally, drying may contribute to the lower amount of adsorbed water by leading to fibre collapse and thus to the reduction of the surface available for adsorption (Marton et al., 1993; Weise and Paulapuro, 1999).

The enzymatic treatment of both the secondary and primary pulps does not significantly affect the amount of water adsorbed in the fibres. However, the strength of the fibre-water interaction is higher for the enzymatically treated samples (Table III), as previously observed by Dourado et al. (1999) for pure celluloses (Table II). In all, these results show that enzymes increase the fibres surface hydrophilicity, probably by increasing the amount of hydrophilic groups, which contribute for a stronger adhesion between the water molecules and the treated surfaces. This effect is probably responsible for the fibres stabilisation in aqueous suspension, which may be useful for paper production, by leading to better paper sheet formation. The aggregation of fibres in aqueous suspension is entropically driven. The water molecules adsorbed in crystalline regions of the fibres have higher free energy (lower entropy) than those in solution, and consequently the "trapped" molecules migrate to the solution, where the free energy is lower; the process favours fibre-fibre contact: fibres aggregate through hydrophobic interaction in crystalline regions. The enzymatic fragmentation, or stabilisation, of cellulose aggregates in aqueous solution was previously reported (Gama et al., 1996; Dourado et al., 1999), and was attributed to hydration and steric effects. As pointed out by Israelachvili (1992), repulsive hydration forces arise whenever water molecules bind strongly to hydrophilic surface groups, because of the energy needed to dehydrate these groups as two surfaces approach each other. When fibres bear adsorbed proteins on the surface, thermal motion gives rise to steric repulsion.

Modification of fibre surface properties gives rise to pulps with a lower SR degree. It must be stressed that, although having a higher water affinity, the fibres adsorb the same amount of water (Table III); it is the stronger fibre-water interactions that

TABLE III Thermal analysis results for the paper pulp samples

\begin{tabular}{|c|c|c|c|c|}
\hline & \multicolumn{2}{|c|}{ Secondary pulp } & \multicolumn{2}{|c|}{ Primary pulp } \\
\hline & $\begin{array}{c}\text { Adsorbed water* } \\
\left(m g \mathrm{H}_{2} \mathrm{O} / m g \text { dry solid } \pm \% \mathrm{CV}\right)\end{array}$ & $\begin{array}{c}\text { Enthalpy of dehydration* } \\
\left(\mathrm{J} / \mathrm{g} \mathrm{H}_{2} \mathrm{O} \pm \% \mathrm{CV}\right)\end{array}$ & $\begin{array}{c}\text { Adsorbed water* } \\
\left(m g \mathrm{H}_{2} \mathrm{O} / m g \text { dry solid } \pm \% \mathrm{CV}\right)\end{array}$ & $\begin{array}{l}\text { Enthalpy of dehydration* } \\
\quad\left(\mathrm{J} / \mathrm{g} \mathrm{H}_{2} \mathrm{O} \pm \% \mathrm{CV}\right) \\
\end{array}$ \\
\hline Blank & $0.20 \pm 5.0$ & $2460 \pm 11.4$ & $0.57 \pm 5.3$ & $2380 \pm 5.5$ \\
\hline Control (15 min) & $0.23 \pm 4.3$ & $2370 \pm 3.8$ & $0.45 \pm 2.2$ & $2120 \pm 7.1$ \\
\hline $\begin{array}{l}\text { Enzymatic } \\
(15 \text { min })\end{array}$ & $0.22 \pm 9.1$ & $2520 \pm 4.4$ & $0.49 \pm 2.0$ & $2350 \pm 5.1$ \\
\hline Control (4h) & $0.22 \pm 9.1$ & $2730 \pm 7.0$ & $0.51 \pm 3.9$ & $2190 \pm 6.8$ \\
\hline Enzymatic (4h) & $0.20 \pm 5.0$ & $3010 \pm 5.6$ & $0.48 \pm 1.0$ & $2190 \pm 6.4$ \\
\hline
\end{tabular}

*\% CV: \% coefficient of variation. 
provide for fibre stabilisation in water, improving the pulp drainability. This topic is further discussed below.

\section{Fibre Cake Permeability}

The drainage behaviour of a fibrous suspension is very complex and influences the papermaking process. Traditional tests, performed with the Schopper-Riegler apparatus or the "Canadian Standard" Freeness Tester, are currently reported as a good basis to provide information on drainage. However, they do not take into account the mechanisms involved in the papermaking process. As the Schopper-Riegler degree is measured without the application of vacuum, shear and the pressurization of the pulp pad do not occur. There is also no indication of the interdependence of sheet structure and drainage. As a consequence, fibre suspensions with the same drainage index $\left({ }^{\circ} \mathrm{SR}\right.$ or CSF) may behave quite differently in the papermachine. Several authors have discussed these problems, and different proposals have been presented to simulate the mechanisms that control drainage in the forming table (Ingmanson, 1964; Sampson, 1997; Attwood and Jopson, 1998; Wildfong et al., 2000).

In the present work, a filtration system operating under steady-state conditions was used to evaluate the pulp dewatering ability expressed as a permeability coefficient $(B)$. The results obtained are compared with the Schopper-Riegler values ( $\left.{ }^{\circ} \mathrm{SR}\right)$. The permeability coefficient is a measure of the fibre porous medium resistance to the water flow. Other parameters were determined, such as the pulp mat resistance $(\alpha)$, compressibility $(s)$ and porosity $(\epsilon)$. The objective of this study is to tentatively identify how the enzymes affect the pulp dewatering properties under the SchopperRiegler assay experimental conditions: different fibre mat characteristics reflect different pulp behaviour during mat formation, which can provide further information about enzymatic modification of fibres.

Baldwin (1996) has reported that a well-formed sheet improves vacuum dewatering. Indeed, when the fibre mat is not uniform, water will take the path of least resistance causing preferential dewatering areas. Ingmanson (1964) showed that the fibre concentration in the suspension greatly affects the mat structure, by altering the way fibres deposit themselves in the forming mat. According to this author, at the same weight basis and pressure drop, higher consistencies are responsible for a higher porosity, and consequently for lower mat resistance to flow. Additionally, a higher consistency requires longer forming periods to achieve mat compression equilibrium. These considerations were taken into account during the filtration assays: the same concentration was used in all replicate assays of each tested experimental condition. The formation period was established in preliminary assays, where the moment when the fibre cake height was constant was determined.

The results in Table IV show that fibre cakes prepared with the primary and the secondary fibre samples have different properties. As expected, the primary fibres produce a less compressible fibre mat, with a higher permeability (B) to water flow: the never-dried fibres show better resistance to collapsing when pressure is applied. Collapsibility is generally related to fibre flexibility (Abitz and Luner, 1995): primary fibres are less flexible (53.62\%) than secondary ones $(63.12 \%)$. This difference is probably related to the intensive manipulation of secondary fibres during previous paper production cycles, which alters the fibre structure (coarseness and fibre wall thickness reduction are known to be responsible for increased elasticity). Considering the different composition and fibre-length of pulps it was also

TABLE IV Permeability assay results

\begin{tabular}{|c|c|c|c|c|}
\hline Sample & $\Delta P\left(\mathrm{~kg} / \mathrm{ms}^{2}\right)$ & $B \pm \% C V\left(m^{2}\right)^{*}$ & $\alpha\left(m^{-2} / g\right.$ dry pulp $)$ & $\epsilon \pm \% C V^{*}$ \\
\hline \multirow[t]{2}{*}{ Primary pulp } & 392 & $1.09 \times 10^{-8} \pm 14$ & $4.55 \times 10^{7}$ & $0.91 \pm 1$ \\
\hline & 13,328 & $8.97 \times 10^{-10} \pm 7$ & $5.54 \times 10^{8}$ & $0.88 \pm 2$ \\
\hline \multirow[t]{2}{*}{ [Drainage rate: $13^{\circ} \mathrm{SR}$ ] } & 39,984 & $9.33 \times 10^{-11} \pm 7$ & $2.61 \times 10^{9}$ & $0.76 \pm 3$ \\
\hline & 66,640 & $2.20 \times 10^{-11} \pm 12$ & $1.11 \times 10^{10}$ & $0.75 \pm 2$ \\
\hline \multicolumn{5}{|l|}{ Compressible cake equation: $\alpha=101,620 \times \Delta P^{0.98}$} \\
\hline \multirow[t]{2}{*}{ Secondary pulp } & 196 & $1.21 \times 10^{-9} \pm 10$ & $4.07 \times 10^{8}$ & $0.93 \pm 2$ \\
\hline & 13,328 & $2.55 \times 10^{-11} \pm 8$ & $1.93 \times 10^{10}$ & $0.85 \pm 2$ \\
\hline \multirow[t]{2}{*}{ [Drainage rate: $41^{\circ} \mathrm{SR}$ ] } & 39,984 & $6.26 \times 10^{-12} \pm 16$ & $7.87 \times 10^{10}$ & $0.83 \pm 2$ \\
\hline & 66,640 & $1.64 \times 10^{-12} \pm 11$ & $2.00 \times 10^{11}$ & $0.80 \pm 1$ \\
\hline \multicolumn{5}{|l|}{ Compressible cake equation: $\alpha=1,641,301 \times \Delta P^{1.0}$} \\
\hline \multirow[t]{3}{*}{ Enzymatic secondary pulp ( $30 \mathrm{~min}, 0.4 \mathrm{FPU})$} & 196 & $8.26 \times 10^{-10} \pm 3$ & $6.05 \times 10^{8}$ & $0.91 \pm 0$ \\
\hline & 13,328 & $5.40 \times 10^{-12} \pm 32$ & $9.26 \times 10^{10}$ & $0.83 \pm 2$ \\
\hline & 39,984 & $1.27 \times 10^{-12} \pm 6$ & $2.62 \times 10^{11}$ & $0.81 \pm 3$ \\
\hline [Drainage rate: $36^{\circ} \mathrm{SR}$ ] & 66,640 & $1.05 \times 10^{-12} \pm 15$ & $3.17 \times 10^{11}$ & $0.77 \pm 5$ \\
\hline Compressible cake equation: $\alpha=1,893,618 \times \Delta P^{1.1}$ & & & & \\
\hline
\end{tabular}

* \% CV: \% coefficient of variation. 
expected that the secondary pulp mat would be more compact than the primary pulp: primary fibres are longer and present fewer fibrils; secondary pulps include "filler material" (fines, dirt, additives). The presence of small particles such as fines, even in low proportion, may not give rise to a significant reduction in porosity, but nevertheless permeability reduces drastically, as was shown in a recent work (Mota et al., 2001).

In these assays, the Schopper-Riegler values agree with the permeability determinations. For example, when comparing the permeability values obtained for a pressure drop of $13,328 \mathrm{~kg} / \mathrm{ms}^{2}$, a SR of $13^{\circ}$ corresponds to a permeability of $8.97 \times 10^{-10} \mathrm{~m}^{2}$ for the primary pulp and a SR of $41^{\circ}$ corresponds to a permeability of $2.55 \times 10^{-11} \mathrm{~m}^{2}$ for the secondary pulp, thus indicating a lower drainability.

When enzymatically-treated and non-treated secondary pulps are compared, this correlation can no longer be established. Although the ${ }^{\circ} \mathrm{SR}$ values reveal that enzymes are able to increase the pulp drainability (a 5 point reduction is observed), the filtration method shows a decrease in the pulp permeability coefficient (a value of $5.40 \times 10^{-12} \mathrm{~m}^{2}$ was obtained for the same pressure drop as above), which was accompanied by a reduction in cake porosity (a reduction from 0.85 to 0.83 ). This contradiction is due to the measuring principle used in the two methods: in the Schopper-Riegler device the drainage rate of a very diluted suspension
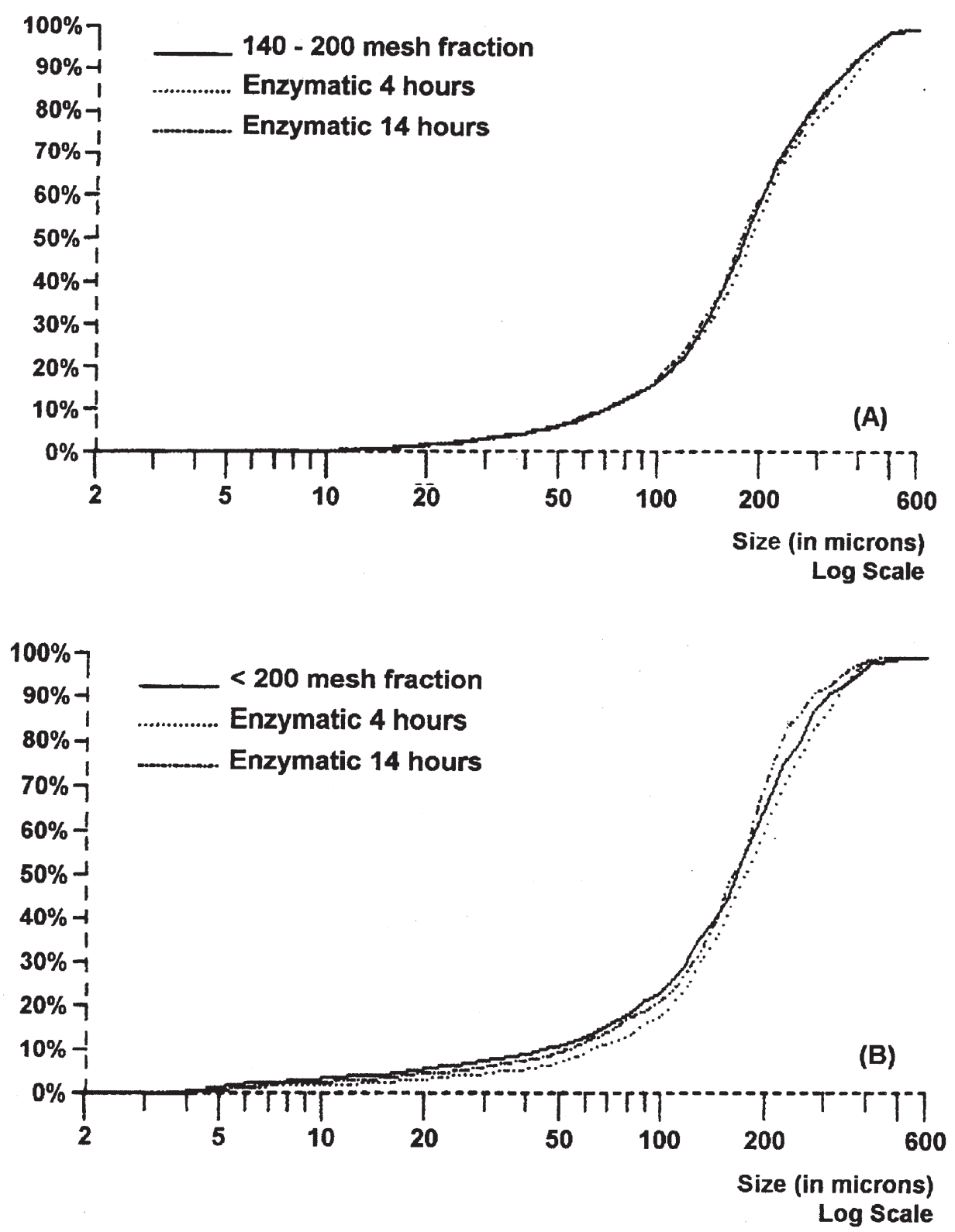

FIGURE 1 Cumulative size distribution curves obtained during the enzymatic treatment of the secondary fibre fractionated samples using Galai CIS-100 analysis. (A) 140-200 mesh fraction and (B) $<200$ mesh fraction. 
$(0.2 \%)$ is measured and the fibre mat has very little influence on how the water drains.

In the case of the cake filtration method, the effect of the fibre mat on the water flow is very important. In these assays, not only the amount and initial dilution of pulp used are important, but also the way in which fibre arranges itself in the mat (Ingmanson, 1964; Baldwin, 1996). It seems that although water is more easily removed from the treated fibres in the Schopper-Riegler apparatus (probably due to the increased fibre surface stability in the presence of the adsorbed enzymes, as it was previously suggested), the fibre cake formed with these fibres is less permeable to water (Table IV). According to the porosity measurements, the arrangement of the treated fibres is more compact, perhaps due to the fragmentation of fibre aggregates and increased fibre flexibility (WFF was measured after $15 \mathrm{~min}$ and $4 \mathrm{~h}$ in both control and enzyme-treated pulps: 63.45 versus $64.81 \%$ and 66.42 versus $67.24 \%$, respectively). It must be underlined that the enzymatic treatment responsible for the changes observed on the permeability assays leads to $1 \%$ of fibre conversion to soluble sugars. This means that solubilisation of fines and small fibres occur to a low extent. As shown before, a variation in the size of the smaller fibres was not detected with low hydrolysis. It seems then that enzymes give rise to two opposing phenomena. On one hand, enzymes stabilise diluted suspensions of fibres (Schopper-Riegler apparatus) leading to a better water flow. On the other hand, enzymes increase the amount of fines, the resulting small particles cause a lower porosity and permeability is reduced.

\section{Particle Size Characterisation}

The scanning laser measurements are accurate essentially when we are dealing with spherical particles, as the shape of irregular particles may distort the time of flight pattern of the particles (CIS100 Operation Manual, 1994; Kaye and Trottier, 1995; Gama et al., 1996). Wood fibres are flat and elongated. Nevertheless, the Galai CIS-100 was tested in the present work, aiming at detecting variation in the size distribution of fines following the enzymatic treatment. The secondary pulp was fractionated and two of the smaller fibre-length fractions were analysed (Fig. 1). The results obtained will of course be considered as a measure of relative size, only.

The Galai analysis did not show any major modification of the fibre size distribution in the 200-140 mesh fibre-fraction (209-297 $\mu \mathrm{m})$ following enzymatic attack (measurements at $30 \mathrm{~min}, 4$ and $14 \mathrm{~h}$ ). Indeed, only a slight modification on the average fibre size in the $<200$ mesh recycled fibre fraction $(<209 \mu \mathrm{m})$ was noticeable: it appears that after a 4-h reaction period, the enzymes are responsible for the degradation of the smaller particles, thus allowing for a slight increase in the average particle size. After $4 \mathrm{~h}$ treatment of the fractions, $4-6 \%$ of the fibres were released as soluble sugars.

Considering that the fibre size distribution profiles do not change significantly in a period of less than $4 \mathrm{~h}$ (Fig. 1), the enzymatic removal of fines cannot explain the drainage increase after a 30-min enzymatic treatment (Table I). Again, it seems likely that enzymes prompt the ${ }^{\circ} \mathrm{SR}$ reduction by stabilising the fibres, as proposed in the previous sections. In fact, it should be remarked that in the present assays, fragmentation was not observable because the fractionated samples include only fines and small fibres. In the presence of longer wood fibres, aggregates would probably break down, leading to the release of the small fines adhered to the large fibres.

\section{CONCLUSIONS}

The Schopper-Riegler measurements indicate a higher drainage rate for the enzymatically treated samples in a very dilute suspension. The fibre cake permeability assays show that the cake formed with the treated fibres is less permeable to water flow; according to this assay the treated fibres may arrange themselves more densely, probably due to fragmentation of fibre aggregates. Both results, SchopperRiegler and cake filtration, may be interpreted as a consequence of fibres stabilisation by the enzyme molecules adsorbed on their surface.

The thermal analysis revealed that, after enzyme adsorption, the water adsorbed onto the fibres is more strongly bound. The presence of protein leads to steric hindrance and to an increase in the strength of water molecule adsorption. This may be responsible for fibre stabilisation.

Indeed, the pulp treatment with Cellulose-binding domains (Table I) confirms that the modification of interfacial properties caused by protein adsorption is of great importance to the enzymes action over the fibres.

\section{References}

Abitz, P. and Luner, P. (re-print 1995) "The Relationships of Wet Fiber Flexibility (WFF) to Fiber and Pulp Properties", Empire State Paper Res. Association Report \#94, Chapter V.

Attwood, B.W. and Jopson, R.N. (1998) "Dynamic drainage simulation", Paper Technology 39(4), 53-56.

Baldwin, L. (1996) "High vacuum dewatering", Paper Technology 38(6), 23-28

Bernfeld, P. (1955) Methods in Enzymology (Collowick S.P. and Kaplan N.D., New York) Vol. 1, pp. 149-152.

Bertran, M.S. and Dale, B.E. (1986) "Determination of cellulose accessibility by differential scanning calorimetry", Journal of Applied Polymer Science 32, 4241-4253. 
Bradford, M.M. (1976) "A rapid and sensitive method for the quantification of microgram quantities of protein utilising the principle of protein-dye binding", Analytical Biochemistry 72, 248-254.

Brown, M.E. (1988) "Introduction to Thermal Analysis: Techniques and Applications", (Chapman and Hall, London), pp. 5-49.

Clark, J.D.A. (1985), Chapter 17, Pulp Technology and Treatment for Paper, 2nd Ed. (Miller Freeman Publications, USA).

Coulson, J.M. and Richardson, J.F. (Trad. CR Carlos) (1984). Tecnologia Química, edited by Fundação Calouste Gulbenkian, 2nd Ed., Vol. II, pp. 1-17 and 53-69.

Cyberflex User Manual (1999), edited by CyberMetrics.

Dourado, F., Mota, M., Pala, H. and Gama, F.M. (1999) “Effect of cellulase adsorption on the surface and interfacial properties of cellulose", Cellulose 6, 265-282.

Galai CIS-100 Operation Manual (1994), edited by Galai Production, Ltd.

Gama, F.M., Carvalho, M.G., Figueiredo, M.M. and Mota, M. (1996) "Comparative study of cellulose fragmentation by enzymes and ultrasound", Enzyme and Microbial Techonology 20, 12-17.

Harakeyama, T. and Quinn, F.X. (1995) "Thermal Analysis: Fundamentals and Applications to Polymer Science", 2nd Ed (Wiley, Chichester), pp. 1-105.

Henrissat, B. (1994) "Cellulases and their interaction with cellulose", Cellulose 1, 169-196.

Hindeleh, A.M. and Johnson, D.J. (1972) “Crystallinity and crystallite size measurement in cellulose fibres: 1. Ramie and Fortisan", Polymer 13, 423-430.

Hindeleh, A.M. and Johnson, D.J. (1974) "Crystallinity and crystallite size measurement in cellulose fibres: 2. Viscose rayon", Polymer 15, 697-705.

Hindeleh, A.M. and Johnson, D.J. (1978) "Crystallinity and crystallite size measurement in polyamide and polyester fibres" Polymer 19, 27-32.

Ingmanson, W.L. (1964) "Filtration of high-consistency fibre suspensions", Tappi Journal 47(12), 742-750.

Israelachvili, J. (1992) Intermolecular and Surface Forces, 2nd Ed (Academic Press, New York), p 399.

Jackson, L.S., Heitmann, J.A. and Joyce, T.W. (1993) “Enzymatic modifications of secondary fibre", Tappi Journal 76(3), 147-154.

Kaye, D.H. and Trottier, R. (1995) "The many measures of fine particles", Chemical Engineering, 78-86.

Lemos, M.A., Teixeira, J.A., Mota, M. and Gama, F.M. (2000) “A simple method to separate cellulose-binding domains of fungal cellulases after digestion by a protease", Biotechnology Letters 22, $703-707$.
Mansfield, S.D., Wong, K.K.Y., De Jong, E. and Saddler, J.N. (1996) "Modification of Douglas-fir mechanical and Kraft pulps by enzymatic treatment", Tappi Journal 79(8), 125-132.

Marton, R., Brown, A., Granzow, S., Koeppicus, R. and Tomlinson, S. (1993) "Recycling and fibre structure", Progress in Paper Recycling, 58-70.

Mota, M., Teixeira, J.A., Bowen, W.R. and Yelshin, A. (2001) "Binary spherical particle mixed beds: porosity and permeability relationship measurement", Transactions of the Filtration Society 1(4), 101-106.

Nazhad, M.M. and Paszner, L. (1994) "Fundamentals of strength loss in recycled paper", Tappi Journal 77(9), 171-179.

Pala, H., Lemos, M.A., Mota, M. and Gama, F.M. (2001) "Enzymatic upgrade of old paperboard containers", Enzyme and Microbial Technology 29, 274-279.

Pere, J., Siika-aho, M., Buchert, J. and Viikari, L. (1995) “Effects of purified Trichoderma reesei cellulases on the fiber properties of kraft pulp", Tappi Journal 78(6), 71-78.

Petit-Conil, M., Passas, R., Cleuet, J.C., Fournier, R. and Voillot, C. (1999) "Fibre characterisation for understanding the effect of plate pattern on TMP and RMP quality". Paper Technology Symposium.

Pommier, J.C., Fuentes, J.L. and Goma, G. (1989) “Using enzymes to improve the process and the product quality in the recycled paper industry", Tappi Journal 72(6), 187-191.

Ryan, S.E., De Jong, E., Gubitz, G.M., Tuohy, M. and Saddler, J.N. (1998) "Enzymatic modification of pre-treated Douglas-fir refiner pulp" 7th International Conference of Biotechnology in the Pulp and Paper Industry, C147-C150.

Sampson, W.W. (1997) "The interdependence of sheet structure and drainage", Paper Technology 38(8), 45-50.

Stork, G. and Puls, J. (1994) "Change in properties of different recycled pulps by endoglucanase treatment", Biotechnology in the Pulp and Paper Industry, 145-150.

Viesturs, U., Leite, M., Treimanis, A., Eremeeva, T., Apsite, A., Eisimonte, M. and Jansons, P. (1996) "Production of cellulases and xylanases by Trichoderna viride and biological processing of lignocellulose and recycled paper fibers", Applied Biochemistry and Biotechnology 57/58, 349-360.

Weise, U. and Paulapuro, H. (1999) "Effect of drying and rewetting cycles on fibre swelling", Journal of Pulp and Paper Science 25(5), 163.

Wildfong, V.J., Genco, J.M., Shands, J.A. and Bousfield, D.W. (2000) "Filtration mechanics of sheet forming. Part I: Apparatus for determination of constant-pressure filtration resistance", Journal of Pulp and Paper Science 26(7), 250-254. 